\title{
ORDEM E SUBVERSÃO NO MOVIMENTO PSICANALÍTICO: O FANTASMA DE JUNG*
}

Michel Plon

Psicanalista, diretor

de pesquisa do

CNRS, membro do

Centro de Pesquisa

Universitária

Psicanálise e

Práticas Sociais da

Saúde, CNRS/

Université de

Picardie, França.
RESUMO: 0 autor procura destacar a presença de Jung na correspondência de Freud com os principais discípulos, no contexto histórico da constituição do movimento psicanalítico e no desdobramento mais importante do mesmo. Vale edizer, a figura de Jung como fantasma no discurso psicanalítico se articula com uma série de problemáticas não apenas teóricas, mas também políticas e institucionais, de maneira que as ressonâncias atuais desta polêmica continuam ainda presentes na psicanálise contemporânea.

Palavras-chave: Jung, ecletismo, sexualidade.

ABSTRACT: Jung's ghost. The author tries to highlight Jung's presence in the mail exchange with his main disciples, in the historic context of the constitution of the psychoanalytic movement and in its most important unfolding. It should be said that the figure of Jung as a ghost in the psychoanalytic discourse is articulated with a number of problems that are not only theoretical, but also political and institutional, so that the current repercussions of that polemic remain.

Keywords: Jung, eclecticism, sexuality.

\section{A Helena Besserman Vianna (in memoriam)}

á que me coube a honra de apresentar a primeira palestra desta jornada, gostaria de agradecer à nossa amiga Elizabeth Roudinesco, insistindo sobre o fato de que devemos a ela nada menos que a própria existência deste encontro. Eque fiqueclaro que estes agradecimentos não são puramente formais, pois, efetivamente, foi de um desejo dela que surgiu este evento, um

\footnotetext{
* Com algumas modificações, esse texto foi uma comunicação no XVI Colóquio da Sociedade Internacional de História da Psiquiatria e da Psicanálise, em 24/ 11/ 2001, em Paris.
} 
desejo que Elizabeth soube sustentar contra tudo e contra todos, não se esquivando de nenhuma das numerosas turbulências que pode ter encontrado em seu caminho.

Como imaginar uma jornada dedicada a Carl Gustav Jung sem levantar também uma questão, ainda que de ricochete, sobre Freud e esse movimento psicanalítico internacional do qual, como todos sabem, o suíço foi o primeiro presidente? A questão se impôs aos membros do comitê organizador deste colóquio assim que acabaram de traçar as diretrizes de seu programa. Seria o caso de falar deFreud e seus colegas em uma reunião consagrada a Jung, mas procurando afastar-se um pouco da narração habitual que se faz sobre a relação entre os dois homens ou, melhor ainda, da ruptura cujas razões todo mundo conhece ou acredita conhecer em detalhe, uma ruptura ainda hoje atual pelos efeitos contemporâneos - como testemunham algumas das dificuldades que poderiam ter conturbado a organização deste encontro - ruptura esta cuja importância se mantém e que não poderia ser mais bem situada que retomando as palavras de Balint em 1944, relembrando as Grandes Controvérsias, que ela continuava a ser a fonte de "feridas não cicatrizadas".

Questionar a especificidade da relação, da ruptura e de seus desdobramentos com ressonâncias infinitamente mais vastas que as produzidas pelo rompimento com Adler ou Steckel, tudo isso abre a questão do lugar de Jung na história da psicanál ise, ou, mais precisamente, a questão do lugar que Freud e os seus, sobretudo o próprio Freud, deram a Jung. Dito de outra maneira - esta idéia me veio há al guns anos ao observar a importância da presença do nome de Jung na correspondência com os outros: Abraham, Ferenczi, Jones, Pfister, Binswanger, LouAndreas Salomé - não se fixar tanto no que foi dito a Jung mas sim no que foi dito deJung.

Ora, o que foi dito de Jung, ao longo de todas essas diversas correspondências impiedosas em sua espontaneidade, põe em jogo essa dimensão particular da história do movimento psicanalítico que constitui a política do próprio movimento, política pensada e impensada, refletida e irrefletida. Em larga medida, essa política, seja qual for o seu registro, é determinada pelo clima, pelo ambiente em que a psicanálise se desenvolve a partir de 1905 e dos anos que se seguiram; um clima que não se pode resumir melhor que Peter Gay (1991) - evocando a criação por Jones, a partir de uma idéia de Ferenczi apoiada por Freud, do famoso Comitê secreto que se realiza em junho de 1912, ou seja, um mês após aquilo que Jung viria a chamar de o "gesto de Kreuzlingen" - quando el e fala do "obsedante sentimento de insegurança em que viviam os primeiros psicanalistas" (p. 265).

Em um primeiro momento, cujo termo podemos situar imediatamente após a ruptura entre os dois homens, esse sentimento de inquietude está ligado ao processo da descoberta, àquilo que implica em audácia, em correr riscos, com uma espécie de euforia ligada ao caráter subversivo de uma diligência que vai ao en- 
contro das idéias recebidas, dos preconceitos e das certezas de todas as ordens. A política que se seguiu foi uma política de conquista, de expansão em todas as direções - e podem se multiplicar as metáforas militares utilizadas por Freud, especialmente na correspondência com Jung - uma política que implicava saber encontrar aliados para sair do enclausuramento vienense e do confinamento judaico que constituíam uma limitação ao desenvolvimento e à difusão da descoberta. N esse contexto de uma estratégia ofensiva, Jung representa um elemento fundamental: não era judeu, era ariano, natural de Zurique, não era vienense, e Freud elabora muito rapidamente - talvez rápido demais, como os exemplos deixam entrever - uma política que deve fazer dele o delfim, o herdeiro, o chefe, mas também o artesão da arianização da psicanálise e com o mesmo ardor e celeridade com que os dissabores se acumulavam em Viena, com Adler eStekel. Para ilustrar esse aumento de poder, quer se tratasse do desejo de arianização da psicanálise ou do desejo de descentralizar o governo do "Império" - a palavra é de Freud em uma carta a Binswanger, de 14 de março de 1911, "o império que fundei" (FREUD \& BINSWANGER, 1992, p. 129), está escrito, e que Jung "deve herdar" - e eu não relembrarei mais que umas poucas, das célebres declarações que vocês todos conhecem: "Sejam tolerantes", escreve Freud aAbraham, em 3 de maio de 1908,

"e não se esqueçam que, de fato, seguir meus pensamentos é mais fácil para vocês do que para Jung (...) por pertencermos à mesma raça vocês estão mais próximos de minha constituição intelectual, enquanto ele, como cristão efilho de pastor, encontra seu caminho em minha direção lutando contra grandes resistências internas. Sua adesão tem, portanto, mais valor. Eu quase diria quefoi apenas depois de sua chegada que a psicanálise escapou do perigo de tornar-se um negócio próprio da nação judaica". (FREUD \& ABRAHAM, 1969, p. 42)

Abraham encontrará nessas palavras freudianas um conforto em relação ao estranhamento precoce com Jung, cuja tensão não foi escondida de Freud, assim como o fez Jung, que se refere ao estranhamento com rara violência. Alguns dias mais tarde, Abraham responderá: ele também sempre sentira um parentesco intelectual com Freud e "confessará de boa vontade" que é mais fácil caminhar com Freud do quecom Jung. Em 26 de dezembro do mesmo ano, 1908, aindaaAbraham, Freud escreve: "N ossos camaradas arianos nos são absolutamente indispensáveis; sem eles a psicanálise seria presa do anti-semitismo." Quatro anos mais tarde, em 29 de julho de 1912, quando a questão era especular sem grandes ilusões sobre 0 curso dos acontecimentos, Freud enfatiza para Binsw anger a importância do tema em relação a outras questões de divergências: “Existe apenas um fato sério, semitas e arianos ( ou anti-semitas) , que eu gostaria de ver juntos no seio da psicanálise, separam-se novamente, como água eazeite." Freud escreve a Ferenczi (1992, 
p. 175) - elimitar-me-ei a este único exemplo - evocando de maneira alusiva aquilo que dizia ter desejado "prevenir pelo deslocamento ( trata-se do deslocamento do governo do Império) para Zurique, nada menos que a idéia de que "nós, os vienenses" não "somos apenas porcos, mas também judeus". E acrescenta: "Isto, porém, não está impresso".

É de direito, inclusive, sobre esse ponto que nada tem de secundário, perguntar-se em que lugar Freud colocava Jung, o qual, diga-se de passagem, de nada estava informado sobre os desígnios do "Muito honrado senhor professor" sobre o que estava em jogo. 0 que é que Freud não ouve ou não pode ouvir nesse período? Não que Jung tenhafeito, na época, qual quer declaração anti-semita explícita, mas que a violência, que acabamos de lembrar, nos seus propósitos dentro do conflito que 0 opõe naquele momento aAbraham, parece ultrapassar simplesmente o registro teórico. "Não há nada a objetar em Abraham", escreve em 19 de agosto de 1907, "apenas não o acho simpático" (FREUD \& JUNG, 1975, p. 131). Em seguida, menos de um ano depois, como o conflito persistisse, apesar do fato, como acabamos de ver, de Freud ter feito valer aAbraham o interesse que havia em "fazer as pazes" com o suíço, este último diz a Freud: "Não deixo de ter um desprezo indisfarçável por certas particularidades do colega Abraham" (p. 214). E mais, háaqui eali, aquelas "pequenasfrases" que mal podemosacreditar que delas Freud não fizesse caso: assim a resposta de Jung, em 4 de junho de 1907, quando Freud, agradecendo os elogios sobre La gradiva, diz que este livro "nos permite regozijarmo-nos de nossa riqueza" eque Jung responde "acho excelente estafrase de sua última carta, de que podemos nos regozijar da riqueza. Eu me regozijo toda semana da riqueza do senhor evivo das migal has que caem da mesa do rico." É claro que Freud responderá, dois dias mais tarde, para marcar seu assombro, que seja ele o rico de cuja mesa cai alguma coisa para Jung, mas já vimos um Freud - e ainda voltaremos a vê-lo - bem mais mordaz.

Há algo mais perturbador, se pudermos assim dizer, que contribuiria para assentar a tese segundo a qual, à medida que se desenvolvia essa fase da política de expansão da qual Jung constituía uma peça chave, que se tratava mais do fantasma de Jung que do próprio Jung, de uma quimera, ou simplesmente de uma fantasia, como indica a origem grega da palavra fantasma. Defato, como compreender queo desacordo referente àquilo que Peter Gay ( 1991) chama apropriadamente de "a lancinante questão da sexualidade" ( p. 263) tenha eclodido tão tardiamente? Freud não teria lido as sucessi vas declarações de Jung, das quais cito apenas al guns exemplos? Inicialmente e desde muito cedo, se posso assim dizer, nestas linhas do prefácio, datado de 1906, de A psicologia da demência precoce, no qual está escrito que “...fazer justiça a Freud não implica, como muitos temem, submeter-se incondicionalmente a um dogma (...) Por exemplo", prossegue Jung, 
"se eu admito os mecanismos complexos dos sonhos e da histeria, isto não quer dizer que atribuo ao trauma sexual infantil a importância exclusiva que Freud parece Ihe dar. E isto quer dizer ainda menos que dou à sexualidade um lugar tão preponderante, nem que eu reconheça nela a universalidade psicológica que Freud parece postular no papel, sem dúvida enorme, que a sexualidade desempenha na psique." (apud McGuire, 1975, p. 12)

Alguns meses mais tarde, temos a primeira carta de Jung a Freud, em 5 de outubro de 1906: “ ....a gênese da histeria me parece ser predominantemente mas não exclusivamente sexual".

À resposta deFreud, paciente e muito pedagógica, Jung responde com o esboço de uma concepção monista do sistema pulsional, concepção esta que sabemos ser um dos pontos mais importantes do desacordo teórico que estava por vir. 0 fosso sobre a questão da sexualidade, que Freud parece não querer nem ver nem ouvir, continua a ficar mais fundo. Em 19 de agosto de 1907, numa carta em que se manifestam os primeiros ataques ad hominem contra Abraham, Jung insiste:

\footnotetext{
"Gostaria de pedir mais um esclarecimento: o senhor concebe a sexualidade como a mãe de todos os sentimentos? A sexualidade, para o senhor, não é simplesmente um componente da personalidade (ainda que seja em verdade o mais importante) ? (...) Não haverá sintomas histéricos que sejam co-determinados pelo complexo sexual, porém condicionados principalmente por uma sublimação ou por um complexo não sexual ( profissão, situação, etc.) ?"
}

Existe ainda, mas trata-se apenas de uma amostra, aquilo queAbraham, em 11 de maio de 1908, no auge de seu choque com Jung, faz chegar com toda clareza aos ouvidos de Freud, mesmo sabendo de to do o desprazer que iria lhe causar: se ele não achou por bem citar aqueles que foram seus primeiros mestres, no texto para Salzburg, é simplesmente " porque eles se desviam da teoria sexual", escreve o berlinense. Serão necessários mais de cinco anos para que Freud dê crédito a seu amigo, em 26 de outubro de 1913, da justeza de suas idéias, escrevendo então que estava " chocado pela completa analogia que se pode descobrir entre a primeira fuga de Breuer diante da descoberta da sexualidade por trás das neuroses e a concepção que Jung tem da sexualidade. Isto só serve para confirmar ainda mais", aponta Freud com precisão, "que aí reside de fato o ponto central da psicanálise". Será necessário, pois, um tempo para que se dissolva, em todos os sentidos, 0 personagem fantasmático de um príncipe herdeiro fiel, capaz ao mesmo tempo de laicizar a psicanálise, de assegurar sua expansão e seu governo, para que enfim Freud venha a considerar que Jung Ihe "pediu em demasia" - nada menos que 0 essencial, ou seja, a renúnciaà teoria sexual - como confidencia ao pastor Pfister 
em 1 o de janeiro de 1913 (FREUD \& PFISTER, 1966, p. 100). Anteriormente, ao mesmo Pfister Freud teria confiado sua feliz surpresa ao anúncio da vinda de Jung aos Estados Unidos com ele. Ele escreve ao pastor em 13 de junho de 1909: "0 senhor também deve estar estupefato com a grande novidade: Jung vem comigo a Worcester. Para mim isto modifica completamente esta viagem, tornando-a muito mais significativa. Agora estou vivamente interessado no que resultará de tudo isto." No ano seguinte, Jung volta aos Estados U nidos e Freud confia ao pastor a sua angústia, angústia que nos põe na tentação de hoje, no a posteriori, qualificar de premonitória: "estou ansioso por seu retorno. Que seria de mim se meus suíços me abandonassem?" (FREUD \&JUNG, 1975, p. 70, carta de 17 de março de 1910). Ao mesmo Pfister, dois meses mais tarde, em 2 de maio de 1910, ele diz, a respeito de Jung: "Quero que ele adquira a autoridade que justificará seu lugar à frente de todo o movimento".

Enfim, em 1912, quando os primeiros abalos já se fazem sentir, os que Freud - e não vou me deter nisto agora - procura minimizar, fracionar, distinguindo entre as relações pessoais, afetivas, que considera arruinadas, e as relações profissionais, que ele ainda pensa poder salvaguardar, Jung esboça uma espécie de estranho balanço salvador: "Eu não teria ficado do seu lado se não tivesse um pouco de heresia no sangue" (FREUD \& JUNG, 1975, p. 259, carta de 3 de março de 1912). Heresia! Não subversão ou revolução, ou mesmo a liberação do espírito, mas a heresia no sangue - pensamos no direito do mesmo nome - a heresia que implica a existência, fosse ela impensada, de uma ortodoxia. Freud nada diz sobre esse termo de heresia, ele se defende apenas de toda tentativa de " repressão intelectual", mas curiosamente, 15 anos mais tarde, numa carta a Jones de 22 de outubro de 1927 (FREUD \& JONES, 1998, p. 279), ele qualifica firmemente como "heréticas" as concepções de Joan Riviere, ressaltando que a posição dela contém uma semelhança fatal com a de Jung! Sempre a heresia! Ainda Jung, depois de 15 anos!

Quea descoberta e o novo sejam bem ou pouco estabelecidos, confortados por outros, que provoquem adesões, alianças, ainda assim o sentimento de inquietude persistirá para se deslocar sobre a vertente de uma política de defesa do adquirido, da desconfiança em relação às inovações prontamente assimiladas à ameaça e ao perigo: o hipotético, o inesperado e o subversivo tendem a se tornar certezas e verdade estabelecidas, a nova ordem é por sua vez pensada como intangível.

Mais dura será a queda, para todos, mas de acordo com modalidades que podem surpreender. Feita a ruptura, o nome de Jung, longe de desaparecer como foi o caso de al guns rostos em fotos oficiais dos anos 1930 em M oscou, continuaráa ser muito presente e ainda por muito tempo, ou evocado como o de um espectro que ronda, cuja sombra pesada tentamos afastar, ou invocado para qualificar e estigmatizar toda dissidência, para significar a amplidão de uma ameaça. Da função de garantia múltipla que suas origens, sua pessoa e seu brilho profissional, pareciam 
assegurar aos olhos de Freud, e ainda que todos, de Jones aAbraham, passando por Ferenczi, estivessem apenas meio convencidos da justeza da política de Freud sobre esse ponto - sobre o qual Freud escreveu a Abraham em 9 de novembro de 1913, "eu me deixo de bom grado aconselhar pelos meus amigos, tendo desaparecido a confiança que tinha em meu julgamento político desde que fui enganado por Jung" (notemos a curiosa formulação: ele não diz que ele, Freud, enganou-se sobre Jung) - desta função de garantia, Jung, ou melhor, seu nome passa a uma outra, a que se agarra a trazer de volta a precariedade de uma situação e de uma ordem que se precisa defender.

Isto feito, insensivelmente, o segundo aspecto do sentimento de insegurança prevaleceu: não é mais o caso de conquistar, de convencer e de ganhar, e menos ainda de arianizar, mas de defender e de eliminar, de assegurar a manutenção de um estado, de proteger uma ordem e uma ortodoxia que vai se institucionalizar cada vez mais.

Depois da saída de Jung, e tendo sido resolvida essa questão que Freud chamou de "repugnante" e que podia perturbar 0 andamento "da obra" ( cartaa Jones de $7 / 11$ / 1913), poderia se esperar que toda a energia seria monopolizada pela produção teórica em curso, aquela que dizia respeito ao remanejamento da teoria das pulsões, à elaboração do conceito de narcisismo e construção da metapsicologia. Por qual quer coisa o nome de Jung continua a monopolizar tempo e sobretudo energia sob formas de extrema violência que merece apenas se dizer: assim Freud observa, em uma carta aAbraham de 25 de março de 1914, que "seja notável ver-se como cada um de nós, por seu turno, é tomado pelo impulso de atacar mortalmente a um ponto em que os outros se vejam obrigados a segurá-lo", e alguns meses mais tarde, ao mesmo Abraham, "enfim vemo-nos livres de Jung, esta besta santa, e de seus acólitos" (26/ 7/ 1914). Neste tempo, que se segue ao rompimento, não só o tom vai se acentuar e como também o recurso a estranhas metáforas que, para fazer ouvir o que poderia ter sido uma hostilidade até então proibida, traduzem concepções políticas nada menos que extremistas: Jones escreve a Freud em 13/ 9/ 1913 que o "robusto estômago de Putnam" - o cenário norte-americano jáe essencial, um mês antes da ruptura definitiva - " rejeita sem sombra de hesitação o guisado de Jung, mesmo sendo temperado por uma suspeita de filosofia e de ética que poderia fazer mal a seu paladar". Um mês mais tarde, em 14 de outubro, o galês se regozija de poder ler, "salvos do Jahrbuch" naquele momento ainda sob controle de Jung, alguns artigos "sem sofrer a influência de um ambiente contagioso" (...) "Daqui a pouco", acrescenta, "nossas publicações (...) serão absolutamente puras e distintas dessa sopa aguada (...) e nossa única preocupação será velar para que assim continuem." Todo um programa! Os últimos meses deste ano de 1913 são marcados pelo que podemos efetivamente chamar de "preocupação americana" quenão pára de se concentrar na pessoa de Putnam, 
que Jones teme não compartilhar da atitude deles, duvidando ao mesmo tempo "que pudessem alistá-lo contra Jung" (11/11/ 1913). Longe de se aplacar, a ira contra Jung continua a desenvolver-se ao longo do ano de 1914: Freud escreve a Jones, comentando a leitura de um texto de Constance Long, que esse texto não "traz nenhum traço da infecção suíça" mas, prudente, e o futuro de Constance Long o justificará, acrescenta que isso talvez se deva ao fato de que o texto podeter sido escrito antes que a autora tenha ouvido o "evangelho de Jung" (carta de 19/ 3/ 1914); assim que ficou conhecida o que Jones chama de "a abdicação de Jung", o galês tempera sua própria al egria escrevendo, em 13 de maio do mesmo ano de 1914, que se a questão da presidência foi regularizada, é preciso aguardar novos aborrecimentos: "Jung não está morto", constataJones, "apenas temporariamente derrotado". Mais uma vez a morte!

Em uma carta que marca a necessidade de se tentar tomar uma distância, Freud tenta acal mar esse desencadeamento de Jones, tenta pôr uma certa ordem ali onde parecem reinar a impulsividade e o ódio, que ele próprio já tinha sentido e alimentado: "Estou desolado", escreve em 2 de junho de 1914, "que você siga os fatos e os gestos [ os de Jung] com tanta inquietação. [N ovamente a inquietação] É inevitável que ele siga seu caminho, que cumpra sua missão (...) termine por personificar algumas das resistências que a Psicanálise encontrará em seu caminho. Eu não estou nem um pouco inquieto com o que ele fabrica mas afirmo que ninguém pode prever o que fará. Nem mesmo Deus ou o Diabo, talvez [!!!] saibam grande coisa do que anda fazendo. Não acho necessário que vocêo ‘ siga passo a passo na Inglaterra ...", e Freud acrescenta, com muita felicidade, uma pitada de humor ao evocar a leitura que acabara de fazer de um texto de Jung sobre a psicose, texto em que este último não esconde sua adesão às idéias de Bergson: “Assim vocês vêem que ele encontrou um outro judeu para seu complexo do pai. Já não estou mais ciumento". Gostaríamos de acreditar!

A guerra, a verdadeira, será responsável por uma relativa calmaria nessa campanha anti-Jung. No entanto, quatro anos de matanças, de penúria e de isolamento não bastaram para fazer desaparecer o espectro de Jung, apesar de todos os avanços teóricos deFreud. Em 1919, quando Jones não cessava de batal har justamente contra a influência junguiana nos Estados Unidos e na Grã-Bretanha por meio de intervenções escritas, Freud o felicita por sua ação institucional: "Sua intenção de depurar a Sociedade de Londres de seus membros junguianos é excelente", escreve em 18 de fevereiro. 0 tema da depuração e de suas conotações al go nauseabundas quejá estavam presentes no momento da rupturafazem assim seu retorno na pluma de uns e outros: "Jung participa aqui de um colóquio no mês que vem", escreve Jones a Freud em 3 de junho de 1919, "e temo que seja bem acolhido, pois ele também tem seus adeptos aqui. Parece impossível cultivar flores sem que cresçam igualmente ervas daninhas; os fenômenos são interligados". Ao mesmo tempo, 
em maio de 1919, Freud faz críticas a Pfister falando de suas escapadas e das da Associação suíça; segundo ele, ninguém parece se dar conta de quea "junguização" sem dúvida penetrou mais profundamente "neles do que gostariam de confessar". As censuras e os atos de contrição da parte do pastor se sucederão ainda por diversos anos até este comunicado triunfante que não se pode ler sem experimentar um certo embaraço, que o pastor enviaa Freud em 23 de outubro de 1923: “Fico feliz em anunciar ao senhor que a mais perfeita ordem reina de novo em nossa Sociedade suíça". Um delegado de polícia não teria dito melhor!

Mas a preocupação com a ordem e com a erradicação, a preocupação com uma pureza preservada de qual quer contaminação, ao abrigo do vírus, não se manifesta apenas no registro desses "negócios" dos quais Freud, numa carta a Jones de 18 de março de 1921, diz que eles "devoram a ciência para todos nós" no plano das decisões políticas. Aparece, mais sutil, como se estivesse enfraquecido mas não menos devastador, sob a forma de um fantasma de domínio teórico que se desenvolve naquela a que cada um empresta não apenas a inteligência mas também 0 rigor e a probidade, Lou, para não deixar de nomeá-la. Numa carta a Freud datada de 20 de junho de 1918 (ANDRÉAS-SALOMÉ, 1970, p. 106), ela comenta os dois ensaios de metapsicologia que ele acabara de lhe enviar e se demora sobre aquele que trata "do melancólico". Ela evoca como parece natural que a humanidade tenha se acreditado cercada de demônios (divinos e também diabólicos, diz ela, eeu comentarei a propósito disto como também de outras coisas, quantos Diabos e Deuses neste negócio!) para constatar "que hoje ainda o pobre Jung foi, um tanto tragicomicamente, vítima de algo análogo. Se soubéssemos exatamente", continua Lou, (permito-me sublinhar o advérbio), se soubéssemos exatamente "de que maneira isto aconteceu a ele, seria, parece-me, de grande importância para a Psicanálise". Fantasia da existência de uma fórmula ou de uma vacina para prevenir todas as dispersões possíveis, fantasia de uma transmissão protegida de todas as formas de aporia, a ferida não cicatrizada continuará por muito tempo a supurar, alimentando com tonalidades bastante inquietantes a fantasi a de uma cura definitiva, de uma saúde inal terável, temática que não deixa de se fazer notar, no a posteriori, como a manifestação, a justificação da boa fundamentação desta conceituação que se pressente estar sendo construída nesses mesmos anos de 18/ 19 eque desembocará na descoberta estrondosa que constituirá a pulsão de morte.

0 fantasma de Jung não está morto. Qualquer crise, por pequena que seja, novamente o convoca. Assim foi em 1924, quando começaram a se manifestar as dificuldades com Rank. Em 20 de março deste mesmo ano, Freud escreve a Ferenczi, (FREUD \& FERENCZI, 2000, p. 149) a quem censurou ter permitido o despertar, na ocasião, do "complexo fraterno" : “Em Rank, felizmente só vejo uma semelhança com o finado Jung [mais uma vez a morte!]: a cegueira causada por suas primeiras experiências pessoais quando se começa a exercer a análise (...) Pondo isto 
de lado, não quero comparar nem as pessoas nem as descobertas. Jung era um patife." A posição deFreud a esse respeito não mudará, ele vai se recusar, com igual sutileza e energia, a assimilar Rank - por mais que este faça a Jung - , apesar da insistência deAbraham que faz o papel de Cassandra e relembra suas advertências de 1908, dizendo em resposta a uma bela carta de Freud de 6 de março de 1924, que suas objeções "não se dirigem aos resultados de Ferenczi e de Rank e sim aos caminhos que eles escolheram. Esses caminhos, acrescenta o berlinense, pensando no exemplo da dissidência junguiana, me parecem conduzir a um racha na psicanálise e é apenas sobre este ponto que incide minha crítica".

Já conhecemos a resposta de Freud, em seguida a uma longa discussão sobre a questão em queAbraham não cessa de proclamar ajusteza de sua "profecia" sobre Jung, "Não é obrigatório que o senhor tenha sempre razão". Diferentemente de Abraham, Lou, a quem Freud confia suas inquietações - sempre a inquietação a propósito de Rank, vai corroborar no sentido da necessária distinção, indo a ponto de minimizar a importância e o contexto da ruptura com Jung - ela escreve em 21 de setembro de 1924: "trata-se de uma preocupação um pouco diferente e mais profunda que a da separação com Adler ou Jung (...) especialmente por tratar-se aqui da prática analítica enquanto que com os outros trata-se de sua concepção do universo".

O fantasma de Jung ainda não desapareceu. Voltando de sua última visita em maio de 1936, por ocasião do discurso que ele tinha proferido respondendo a um convite daAssociação Acadêmica de Psicologia Médica no octogésimo aniversário deFreud, Ludwig Binswanger nota, lacônico: “Falamos sobretudo de Jung, de nossa primeira visita".

Após a morte de Freud, as grandes controvérsias encontrarão em Londres uma nova ocasião para efetuar um come back do fantasma de Jung com a mesma finalidade explícita de fazer reinar a ordem e de banir as divergências: Walter Schmiderberg, expressando vigorosa crítica daquilo que considera o imperialismo kleiniano, evoca a crítica freudiana aJung, trinta anos antes, sublinhando como, não fosse pela presença do nome de Jung no texto freudiano, poder-se-ia crer que era uma crítica a Melanie Klein. A esta aproximação, que evidentemente tem 0 valor de uma condenação inapelável, segue-se 0 alerta de Marjorie Brierley que critica as concepções expostas por Susan I saacs sob a forma de advertência: “Todas as formulações teóricas correm o risco de degenerar em reafirmação de crenças arcaicas. Como mostra o exemplo de Jung, a margem de segurança é estreita", pontifica essa guardiã do templo, entre a criação de uma nova mitologia e a elaboração de uma contribuição válida para o saber. Marjorie Brierley prossegue:

“Manter o rumo é uma questão de ensaio e erro. Mas o narcisismo humano sempre busca um lugar para se meter (...) Devemos na verdade ser muito prudentes para não 
permitir que encontre um último refúgio na realidade psicológica ou na onipotência da fantasia." ${ }^{1}$

M argem de segurança, prudência, interdição, este congelamento que cristaliza o apelo do espectro de Jung, Ana Freud, por sua vez, não se privará dele, evocando a catástrofe que poderia ter sido, segundo ela, a adoção da idéia de fórum aberto proposta pelos Independentes: "Se houvesse sido adotado este procedimento", relembra ela um tanto sentenciosamente, "a Psicanálise de hoje incluiria, por exemplo, os ensinamentos teóricos e técnicos de Stekel, deAdler, de Jung, de Rank, etc." De forma ainda mais grave, se isto for possível, a filha de Freud acrescenta "que um instituto deste tipo foi efetivamente criado em 1934, em Berlim, o Instituto Goering, sob pressão e segundo o voto expresso do regime nazista" . Ana Freud se engana, o Instituto Goering foi criado em Berlim em 1936! Mas isto, claro, não é o essencial: 0 essencial está nesse paradoxo realmente pavoroso que consiste em atribuir indiretamente aos nazistas uma concepção pluralista e tolerante da discussão científica e também, paradoxalmente, não mencionando que este "ecumenismo" tinha como única razão de ser 0 anti-semitismo, em se inscrever no espeIho dos nazistas sob um manto que os separasse deles. Trágico desprezo!

Por um tempo, quimera, por muito tempo, espectro, o fantasma de Jung percorre a história do movimento psicanalítico. Está no coração daquilo que acredito ter podido discernir como sendo as duas formas da política seguida por Freud, seus companheiros e muitos de seus sucessores designados: política de subversão, política de ordem. Mas o fantasma de Jung também estána articulação dos dois termos de um dilema cujas bases e efeitos continuam ainda hoje a caracterizar nosso modo de funcionamento. A menos que, argumentando com o necessário rigor conceitual que veste a armadura implacável do totalitarismo e do sectarismo terrorista, se oponhaà via liberal, plural ou eclética que desemboca inelutavelmente sobre 0 inefável e 0 psicologismo. A violência, o ódio e os votos de morte fazem freqüentemente cortejo à primeira opção, o ridículo, a caricatura e o rechaço fazem eco do outro lado. Serão essas as úni cas opções pensáveis e passaráa sobrevivência da psicanálise pela escolha da primei ra como a história e a atual idade tendem a estabelecer? Não há di lema sem o terceiro termo de seu enunciado. Não seria a hora de os psicanal istas identificarem este terceiro, de se perguntarem sobre a questão dos fundamentos psíquicos desta configuração, sobre as raízes desta violência, do sectarismo sempre renascente, ou devemos pensar que estemodo de funcionamento éinelutável, desde o início rebelde aos efeitos de um trabal ho analítico, seja lá de que ordem for?

Tradução de Helena Floresta de Miranda

Recebido em 12/ 9/2002. Aprovado em 30/ 9/ 2002.

1 Cf. Les controverses Anna Freud et M danie Klèn 1941-1945 (1991-1996), Paris, PUF. 


\section{REFERÊNCIAS}

ANDRÉAS-SALOMÉ, L. (1958/ 1966) Correspondance avec Sigmund Freud, seguida do Journal d' une année (1912-1913) Paris, Gallimard, 1970.

FREUD, S. e BINSWAN GER, L. (1992-1995) Correspondance 1908-1938, Paris, Calmann-Lévy.

e ABRAHAM, K. (1965-1969) Correspondance 1907-1926, Paris, Gallimard.

Lévy. e FERENCZI, S. (1992) Correspondance1908-1914, Paris, Calmanne JUNG, C. (1975) Correspondance 1906-1909, Paris, Gallimard. Correspondance 1910-1914 (1975), Paris, Gallimard, p. 259.

FREUD, S. e JONES, E. Correspondance complète (1908-1939) (1993-1998), Paris, PUF, p. 729. e FERENCZI, S. Correspondance 1920-1923 Les années douloureuses (2000), Paris, Calmann-Lévy, p. 149. . e PFISTER (1963) Correspondance de Sigmund Freud avec le Pasteur Pfister 1909-1939, Paris, Gallimard.

GAY, P. Freud, une vie. (1991-1998) Paris, Hachette.

McGUIRE, W. "Introduction à la correspondance Freud/ Jung" in FREUD, S. e JUNG, C. (1975) Correspondance 1906-1909, Paris, Gallimard.

Miche Plon

Rue du Commandant René Mouchote 75.014 Paris França 